\title{
Reproducibility of Pop-Ins in Laboratory Testing of Welded Joints
}

\author{
C. Berejnoi $^{*}$, J.E. Perez Ipiña ${ }^{\mathrm{b}}$, C.L. Llorente ${ }^{\mathrm{c}}$ \\ ${ }^{\mathrm{a}}$ Facultad de Ingeniería, Universidad Nacional de Salta, \\ Avda. Bolivia 5150, Salta (4400), Argentina \\ ${ }^{\mathrm{b}}$ Grupo Mecánica de Fractura, Facultad de Ingeniería, Universidad Nacional del \\ Comahue/ CONICET, Buenos Aires st. 1400, Neuquén (8300), Argentina \\ ${ }^{\mathrm{c}}$ Comisión de Investigaciones Científicas, Facultad de Ingeniería - Universidad \\ Nacional de La Plata, Calle 48 y 116, La Plata (1900), Argentina
}

Received: August 7, 2000; Revised: November 13, 2000

\begin{abstract}
The pop-in phenomenon, quite common in fracture mechanics tests of welded joints, corresponds to a brittle crack initiation grown from a local brittle zone (LBZ) that is arrested in reaching the higher toughness material that surrounds this LBZ.

A methodology to obtain a high percentage of pop-in occurrence in laboratory testing is necessary to study the pop-in significance. Such a method is introduced in this work and includes the consumable combination and welding procedures for the SMAW welding process to generate artificial LBZ.

In order to find out the influence of the loading state upon the pop-in phenomenon, laboratory CTOD tests were performed using two specimen configurations: some single edge-notched specimens were loaded on a three-point bending $(\mathbf{S E}(\mathbf{B}))$ fixture while others were tested in tensile load $(\mathbf{S E}(\mathbf{T}))$. A higher frequency of pop-in occurrence was observed in the $\mathbf{S E}(\mathbf{B})$ geometry.
\end{abstract}

Keywords: pop-in, local brittle zone, fracture toughness

\section{Introduction}

The material intrinsic heterogeneous (mechanical and metallurgical) properties resulting from any welding procedure bring about some difficulties when fracture mechanics tests of welded joints are performed following the procedures issued in ordinary standards (ASTM E399, E1290, E1820, BS 7448: Part 1). Critical CTOD values are very sensitive to the microstructures surrounding the crack tip and, as it may sample different zones, the test results show large scatter ${ }^{1}$. A very low value of toughness is measured if a local brittle zone ( LBZ) is met by the crack tip.

In fracture mechanics tests of welded joints, small occurrences of brittle crack initiation and arrest are very usual and they appear as discontinuities in the load versus clip gage displacement record (generally a drop in load and an increment in displacement followed by both increment of displacement and load) (Fig. 1). This phenomenon is called pop-in and results from a small brittle crack growth triggered from a LBZ that is subsequently arrested by a material that is supposed of higher toughness that surrounds this

aemail: berejnoi@unsa.edu.ar
LBZ. It is important to know the significance of any pop-in because too conservative values of fracture toughness may be obtained when it is regarded as a critical event ${ }^{2}$.

Pop-ins are normally triggered from LBZ located in the heat affected zone (HAZ), but when different aspects of pop-in are to be studied, performing these tests in $\mathbf{H A Z}$ turns both difficult and time and money consuming because

a) This zone is small and very heterogeneous.

b) Many times the whole or part of the fatigue precrack tip is placed outside the coarse grain sector of the HAZ.

As described above, a high percentage of tests lack pop-ins. It would be very convenient to achieve a methodology which should make a high rate of pop-ins available. It is desirable that this methodology should also allow a high percentage of pop-in production at near room temperature.

Laboratory tests are generally performed under displacement control conditions while actual structures are many times subject to conditions closer to load control than to displacement control. The stress intensity factor may diminish as a consequence of an increment in crack length under constant displacement conditions, and this decrement 


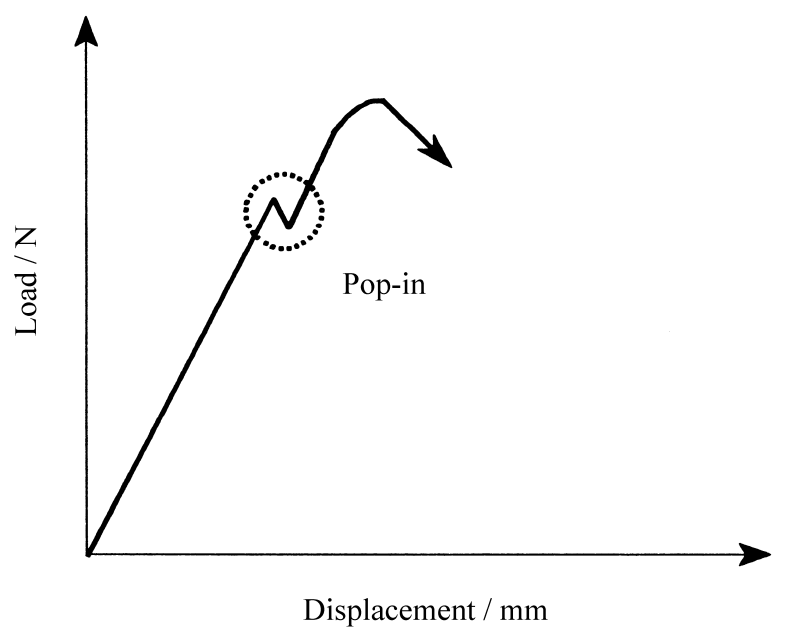

Figure 1. Typical pop-in manifestation in a $\mathrm{P}$ vs. CMOD record.

in load severity is likely to be the cause of the crack arrest. The crack arrest would also be produced by a stress waves reflection in the specimen boundaries close to the crack tip. If a crack is arrested in a specimen due to any of these causes, the same crack would not be arrested in a structural component and consequently a brittle failure would result ${ }^{2-}$ 5

It is important to note that the load state acting over an actual structure may be different from the corresponding load acting over a specimen in a standard test $(\mathbf{S E}(\mathbf{B})$ or $\mathbf{C T}$ specimens), i.e., mainly tension loads instead of bending loads.

A methodology for the generation of pop-ins in laboratory testing is introduced in this work. It includes the search for consumable combination (welding procedure) for the SMAW welding process to generate artificial $\mathbf{L B Z}$, and the choice of the most convenient orientation of the crack regarding the weld direction in order to improve the occurrence of pop-ins at relatively high temperatures (between $-18{ }^{\circ} \mathrm{C}$ and room temperature).

Once the most favorable conditions for the occurrence of pop-ins were selected, the influence of the loading state over the pop-in was studied. In order to do this, tests were performed with some specimens subject to bending loads (SE(B)) and some others subject to tensile loads (SE(T)). The specimens always belonged to the single edge-notched type.
A scanning electronic microscope was used to watch the fracture surfaces of the broken specimens, while an optical microscope was employed to determine the different zones reached by the crack.

\section{Reproducibility of Pop-Ins}

\subsection{Consumable and specimen geometry selection}

Specimens were obtained from A516 grade 70 steel plates (25 mm thickness), and welded using the SMAW process.

In order to produce artificial LBZ, two different electrodes were employed (Fig. 2). Arimochi et al. also used this technique, except that they performed the tests at very low temperatures ${ }^{2}$.

The AWS E6013 electrode was selected for filler beads, while the three electrodes used in the central bead to produce $\mathbf{L B Z}$ were:

- DIN E6-55 (60w) r,

- AWS E7018-A1, and

- AWS E7010-A1.

Table 1 shows chemical and mechanical characteristics of the above mentioned electrodes.

Single edge-notched bending (SE(B)) specimens with square section (BxB)were machined in order to test them within two types of notch orientation (Fig. 3) (In accordance with nomenclature in Ref. 6):

Type 1 specimens 6 TS-W

Type 2 specimens 6 TW-W

The first letter indicates the normal direction to the notch plane, the second letter indicates the expected fatigue

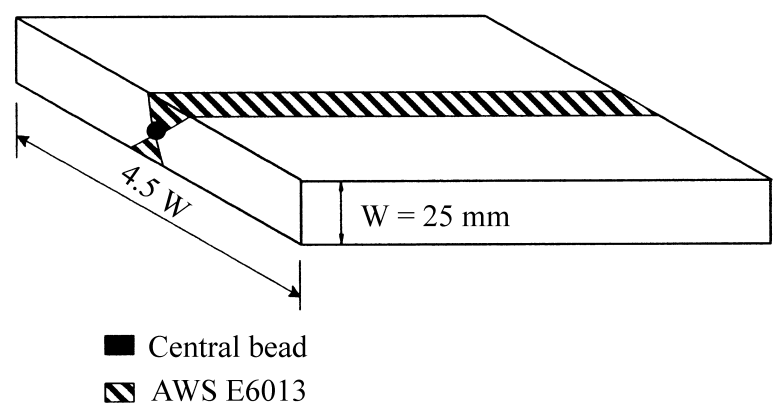

Figure 2. Joint configuration and position of the two electrode types used.

Table 1. Chemical and mechanical characteristics of the electrodes used.

\begin{tabular}{lcccccccc}
\hline \multirow{2}{*}{ Electrode } & \multicolumn{9}{c}{ Chemical composition $(\%)$} & \multirow{2}{*}{$\sigma_{\text {U }}(\mathrm{MPa})$} & \multirow{2}{*}{$\sigma_{\mathrm{Y}}(\mathrm{MPa})$} & \multirow{2}{*}{ Hardness HRC } \\
\cline { 2 - 6 } & $\mathrm{C}$ & $\mathrm{Mn}$ & $\mathrm{Mo}$ & $\mathrm{Si}$ & $\mathrm{Cr}$ & & & \\
\hline AWS E6013 & 0.10 & 0.35 & - & 0.25 & & $500-600$ & $400-500$ & - \\
AWS E7010-A1 & 0.11 & 0.35 & 0.50 & 0.18 & - & $540-640$ & $440-540$ & - \\
AWS E7018-A1 & 0.06 & 0.70 & 0.50 & - & - & $530-630$ & $450-550$ & - \\
DIN E6-55 (60w)r & 0.75 & - & - & - & 7.00 & - & 55 \\
\hline
\end{tabular}


crack growing direction, and the third letter refers to the zone where the crack tip is located (W corresponding to Weld Metal).
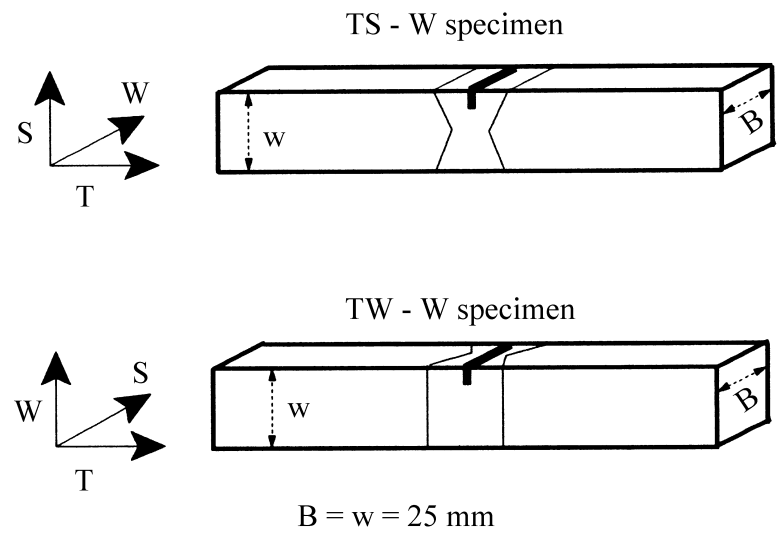

Figure 3. TS and TW geometries.
Sumpter used both TS and TW geometries ${ }^{7,8}$. Arimochi et al. used special designed specimens to produce artificial LBZ: they used consumables with no $\mathrm{Ni}$ for the central bead, while a high Ni content electrode was used as tough filler. $^{2}$ They tested the specimens using a TW geometry at very low temperatures $\left(-120^{\circ} \mathrm{C}<\mathrm{T}<-60^{\circ} \mathrm{C}\right)$. Koçak et al. tested compact specimens at room temperature with the crack tip located at the heat affected zone (HAZ $)^{3}$. They used both transverse and longitudinal crack tip orientation.

Specimen fatigue precracking was performed in accordance with BS 7448: Part $1^{9}$. Previous to fatigue precracking, a mechanical stress relief technique (reverse bending) was performed $^{6}$.

Table 2 shows the specimen dimensions, notch directions, notch types and the electrodes used as central bead.

Table 2. Specimen dimensions, notch characteristics and type of electrode used as central bead.

\begin{tabular}{lcccccc}
\hline Specimen & $\mathrm{B}(\mathrm{mm})$ & $\mathrm{a}_{0} / \mathrm{W}$ & $\mathrm{W}(\mathrm{mm})$ & Notch direction & Notch type & Central bead \\
\hline 1 & 23,05 & 0.506 & 23,56 & TW & Standard & DIN E6-55 (60w) $\mathrm{r}$ \\
2 & 23,05 & 0.333 & 22,85 & TW & Chevron & DIN E6-55 (60w) $\mathrm{r}$ \\
3 & 23,14 & 0.301 & 23,08 & TW & Chevron & DIN E6-55 (60w) $\mathrm{r}$ \\
4 & 23,16 & 0.314 & 22,73 & TW & Chevron & DIN E6-55 (60w) $\mathrm{r}$ \\
5 & 22,6 & 0.311 & 22,65 & TW & Chevron & DIN E6-55 (60w) $\mathrm{r}$ \\
6 & 21,13 & 0.303 & 20,12 & TW & Chevron & AWS E7018-A1 \\
7 & 21,36 & 0.368 & 19,35 & TW & Chevron & AWS E7018-A1 \\
8 & 19,6 & 0.376 & 19,5 & TW & Chevron & AWS E7018-A1 \\
9 & 21,85 & 0.249 & 22 & TW & Chevron & AWS E7018-A1 \\
10 & 21,31 & 0.31 & 19,5 & TW & Chevron & DIN E6-55 (60w) $\mathrm{r}$ \\
11 & 22,3 & 0.322 & 22,3 & TW & Chevron & DIN E6-55 (60w) $\mathrm{r}$ \\
12 & 21,95 & 0.408 & 22 & TW & Chevron & AWS E7018-A1 \\
13 & 19,9 & 0.379 & 20,4 & TS & Standard & AWS E7018-A1 \\
14 & 18,2 & 0.289 & 18,4 & TS & Standard & AWS E7018-A1 \\
15 & 19,8 & 0.316 & 20,2 & TS & Standard & AWS E7018-A1 \\
16 & 22,71 & 0.222 & 22,72 & TS & Standard & DIN E6-55 (60w) $\mathrm{r}$ \\
17 & 19,73 & 0.299 & 19,63 & TS & Standard & DIN E6-55 (60w) $\mathrm{r}$ \\
18 & 22,37 & 0.198 & 22,5 & TS & Standard & DIN E6-55 (60w) r \\
19 & 19,62 & 0.264 & 19,49 & TS & Standard & DIN E6-55 (60w) r \\
20 & 18,05 & 0.292 & 18,48 & TS & Standard & DIN E6-55 (60w) r \\
21 & 22,6 & 0.253 & 22,62 & TS & Standard & DIN E6-55 (60w) r \\
22 & 19,66 & 0.309 & 19,64 & TS & Standard & DIN E6-55 (60w) r \\
23 & 21 & 0.504 & 21,10 & TS & Standard & AWS E7010-A1 \\
24 & 21,61 & 0.446 & 21,56 & TS & Standard & AWS E7010-A1 \\
25 & 21,31 & 0.411 & 21,35 & TS & Standard & AWS E7010-A1 \\
\hline
\end{tabular}

Note: For all the specimens the filler beads were welded with AWS E6013. 


\subsection{Results}

Table 3 and Table 4 show the CTOD $\left(\delta^{*}\right)$ values at maximum load and at pop-in initiation. All tests were performed at room temperature. CTOD values were calculated using the procedure issued in BS 7448: Part 1.

\subsection{Analysis}

1) The "Reverse Bending" technique was effective. Precrack fronts were generally acceptable according to the requirements set forth by BS 7448: Part 1. When DIN
E6-55 [60w] electrode was used as central bead, a chevron notch had to be machined as a consequence of its great hardness. In these cases, the fatigue precrack grew sometimes in two different planes.

2) The welding procedure was effective in producing LBZ for all three electrodes used as central bead, combined with AWS E-6013 electrode as filler bead.

DIN E6-55 (60w) $\mathbf{r}$ electrode presented a poor weldability and it was also too brittle. In some specimens small cracks were observed prior to fatigue precracking. Of

Table 3. CTOD values at maximum load and at pop-in initiation. TW specimens

\begin{tabular}{lcccc}
\hline Specimen & $\begin{array}{c}\delta \mathrm{m} \\
(\mathrm{mm})\end{array}$ & $\begin{array}{c}\delta \mathrm{p}-\mathrm{i} \\
(\mathrm{mm})\end{array}$ & $\begin{array}{c}\text { Notch } \\
\text { direction }\end{array}$ & $\begin{array}{c}\text { Pop-in occurrence with respect to maximum } \\
\text { load plateau }\end{array}$ \\
\hline 1 & 0.16 & - & TW & - \\
2 & 0.15 & - & TW & TW \\
3 & 0.14 & - & TW & - \\
4 & 0.29 & - & TW & - \\
5 & 0.23 & - & TW & - \\
6 & 0.063 & - & TW & coincident \\
7 & 0.24 & - & TW & after \\
8 & 0.058 & 0.058 & TW & before \\
9 & 0.39 & 1.4 & TW & - \\
10 & 0.11 & 0.033 & TW & TW \\
\hline
\end{tabular}

Table 4. CTOD values at maximum load and at pop-in initiation. TS specimens.

\begin{tabular}{|c|c|c|c|c|}
\hline Specimen & $\delta \mathrm{m}(\mathrm{mm})$ & $\delta p-i(m m)$ & Notch direction & $\begin{array}{l}\text { Pop-in occurrence with respect to maximum } \\
\text { load plateau }\end{array}$ \\
\hline 13 & 0.76 & 0.94 & $\mathrm{TS}$ & after \\
\hline 14 & 0.52 & - & $\mathrm{TS}$ & - \\
\hline 15 & 0.53 & 0.17 & TS & before \\
\hline 16 & 0.077 & 0.18 & $\mathrm{TS}$ & after \\
\hline 17 & 0.072 & 0.026 & TS & before \\
\hline 18 & - & 0.21 & $\mathrm{TS}$ & near \\
\hline 19 & 0.053 & 0.053 & $\mathrm{TS}$ & coincident \\
\hline 20 & 0.063 & - & $\mathrm{TS}$ & - \\
\hline 21 & 0.068 & 0.12 & $\mathrm{TS}$ & after \\
\hline 22 & 0.06 & 0.031 & TS & before \\
\hline $23^{\S}$ & 0.30 & - & $\mathrm{TS}$ & - \\
\hline 24 & 0.30 & 0.30 & $\mathrm{TS}$ & coincident \\
\hline 25 & 0.33 & - & TS & - \\
\hline
\end{tabular}

$\S:$ The fracture surfaces of the broken specimen show a small area corresponding to a pop-in. However, load vs. displacement record showed no traces of such pop-in. 
course, such specimens were not tested. This electrode is also very hard, making it difficult to machine the resulting welding bead.

The electrode combinations producing artificial LBZ that proved convenient were:

AWS E6013 - AWS E7010-A1 (central bead), or

AWS E6013 - AWS E7018-A1 (central bead).

3) TS notch orientation proved the most convenient because $76.9 \%$ of the tests (10 over a total of 13) presented pop-ins, whilst only $33.3 \%$ (4 over a total of 12) of the tests with the TW notch direction gave pop-ins (Fig. 4 and Fig. $5)$. It must be noted that in the latter specimens, multiple audible pop-ins were listened to in the linear elastic region, although they were not recorded in the Load vs. Displacement graph because of their small size.

A similar analysis based only on equal consumables showed that the most convenient direction to produce popin was that referred as TS.

4) For AWS E6013 / AWS E7018-A1 and AWS E6013 / AWS E7010-A1 combinations and TS-W orientation, the presence of coarse grains at the brittle initiation point was verified in each specimen that showed pop-in by means of scanning electronic and optical microscopic examinations. Figures 6-a and 6-b are examples of such examinations. The first one corresponds to the optical microscopic examination of the specimen $\mathbf{S E}(\mathbf{T}) \mathbf{- 7}$, and shows that the pop-in was initiated at a coarse grain zone. Figure 6-b is the observation taken by a scanning electronic microscope of the same specimen, and reveals the existence of cleavage zones where the pop-in was supposed to initiate at.

5) Pop-ins are considered more important when they occur before the maximum load plateau and most research on this subject has been focused on this situation, but in testing welded joints of parent materials working in the upper shelf zone this phenomenon is sometimes present at or after the maximum load plateau. As not much work has been performed in the latter situation, we consider that a further study is desirable.

6) It is important to note that this methodology can be used for pop-in occurrence before maximum load plateau simply by lowering the test temperature.

\section{Influence oof the Loading State}

\subsection{Experimental procedure}

In order to find out the influence of the loading state over the pop-in phenomenon, twenty-one laboratory CTOD tests were performed using two specimen configurations: 10 single edge-notched specimens were loaded in a three-point bending fixture $(\mathbf{S E}(\mathbf{B}))$, while the remaining 11 specimens were loaded in tensile mode $(\mathbf{S E}(\mathbf{T}))$. In order to improve the probability of pop-in occurrence the test temperature was $-18{ }^{\circ} \mathrm{C}$. The specimens had a square section ( $\mathrm{B}=\mathrm{W}=20 \mathrm{~mm}$ ) (Fig. 3) with shallow cracks, i.e.

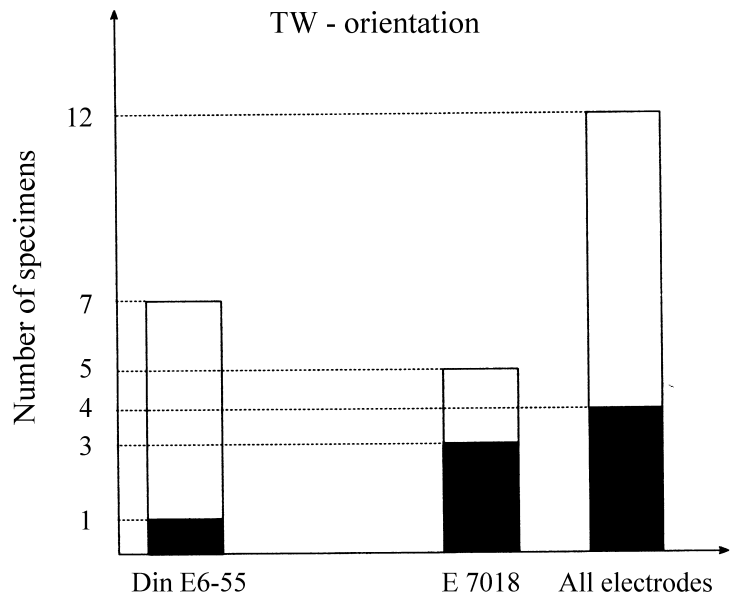

Specimens with pop-in $\square$ Specimens without pop-in

Figure 4. Frequency of pop-in in TW orientation.

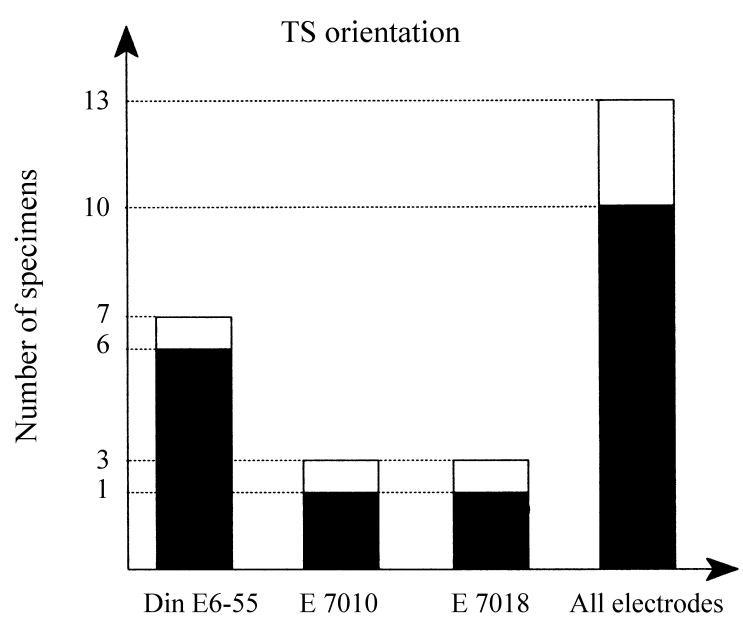

Specimens with pop-in $\square$ Specimens without pop-in

Figure 5. Frequency of pop-in in TS orientation.

TS-W specimens. Prior to fatigue precracking a reverse bending treatment was applied to each specimen.

The consumables combination chosen was: AWS E6013 / AWS E7018-A1.

The CTOD values in $\mathbf{S E}(B)$ tests were calculated measuring the crack mouth opening displacement(CMOD) (Fig. 7 ) in accordance with BS 7448: Part $1^{9}$. Instead, $*_{5}{ }^{10}$ was considered as CTOD value for SE(T) tests and was then directly measured with a clip gage at the specimen surface as shown in Fig. 8.

\subsection{Results}

Tables 5 and 6 show specimen dimensions and CTOD values for $\mathbf{S E}(B)$ and $\mathbf{S E}(\mathbf{T})$ tests respectively. 


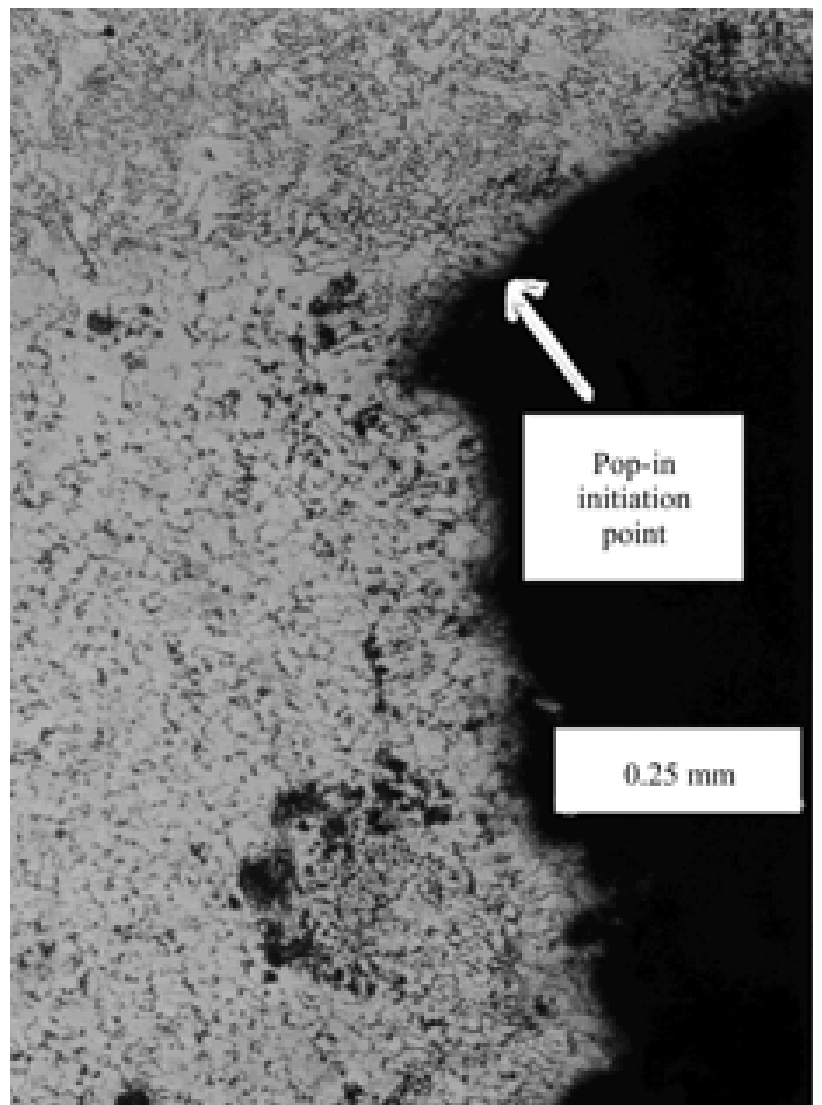

Figure 6a. Micrograph of specimen $\mathrm{SE}(\mathrm{T}) 7$.

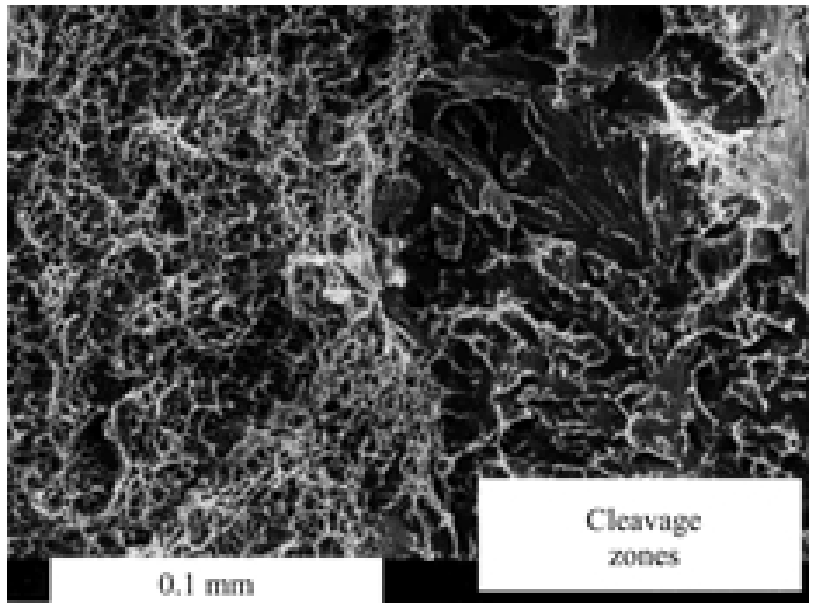

Figure 6b. Pop-in initiation point observed using a scanning microscope (specimen $\mathrm{SE}(\mathrm{T})$ 7).

\subsection{Analysis}

In Table 5 and Table 6 it can be seen that 6 out of 10 SE(B) specimens presented pop-ins, whilst only 4 specimens (out of a total of 11) failed due to pop-in in tensile tests. The frequency of pop-in occurrence is greater in the first tests than in the second ones. This is in accordance with the results of Arimochi et $a l^{2}$, who observed pop-ins at

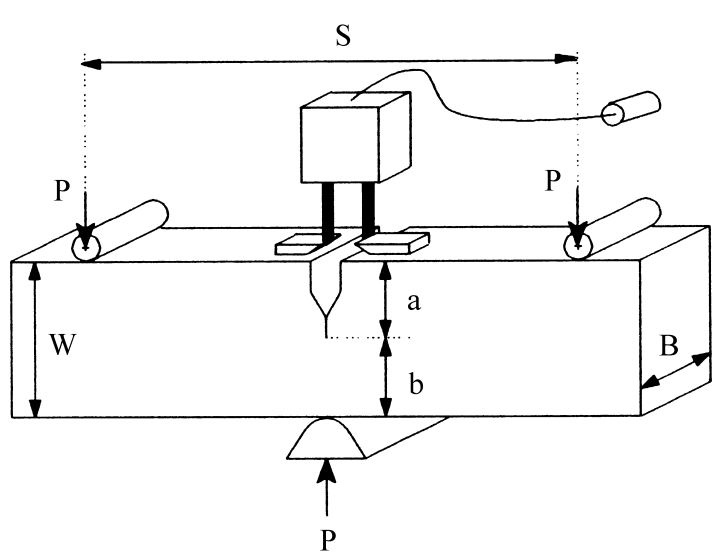

Figure 7. $\mathrm{SE}(\mathrm{B})$ specimen.

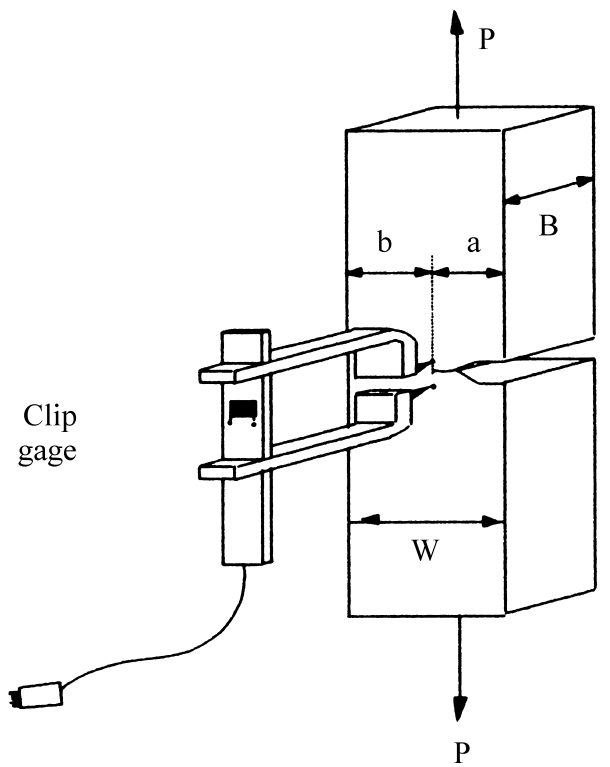

Figure 8. $\mathrm{SE}(\mathrm{T})$ specimen.

different temperature ranges, depending on the loading type. For $\mathbf{S E}(\mathbf{B})$ tests the pop-in phenomenon was present at temperatures between $-70{ }^{\circ} \mathrm{C}$ and $-100{ }^{\circ} \mathrm{C}$, while with wide plates under tensile loads, temperatures between $-100^{\circ} \mathrm{C}$ and $-120{ }^{\circ} \mathrm{C}$ were necessary to observe this phenomenon. This would indicate that the occurrence of a pop-in in a laboratory bend test does not mean that the same behavior should be expected in an actual structure under tensile loading. However, this is not a conclusive observation, and a further study on this subject is necessary.

With Arimochi et al. ${ }^{2}$ results in mind, it is possible to think that the test temperature $\left(-18^{\circ} \mathrm{C}\right)$ corresponds to one in which the pop-in phenomenon might be observed in both $\mathbf{S E}(\mathbf{B})$ and SE(T) tests, being of a higher frequency in the first ones.

Pop-in occurrence depends upon the distance between the crack tip and the $\mathbf{L} \mathbf{B Z} \mathbf{Z}^{2,3}$. If this distance is large, the 
Table 5. CTOD values, three point bending specimens $(\mathbf{S E}(\mathbf{B}))$.

\begin{tabular}{|c|c|c|c|c|c|c|c|}
\hline Specimen & $\mathrm{a}$ & $\begin{array}{c}\mathrm{B} \\
(\mathrm{mm})\end{array}$ & $\begin{array}{c}\mathrm{W} \\
(\mathrm{mm})\end{array}$ & $\begin{array}{c}\mathrm{a} / \mathrm{W} \\
(\mathrm{mm})\end{array}$ & $\begin{array}{c}\delta \mathrm{m} \\
(\mathrm{mm})\end{array}$ & $\begin{array}{c}\text { Spop-in } \\
(\mathrm{mm})\end{array}$ & $\begin{array}{c}\text { Pop-in occurrence with respect to } \\
\text { maximum load plateau }\end{array}$ \\
\hline $\mathrm{SE}(\mathrm{B})-1$ & 10.94 & 19.92 & 19.64 & 0.557 & 0.232 & - & - \\
\hline $\mathrm{SE}(\mathrm{B})-2$ & 9.07 & 19.58 & 19.72 & 0.46 & 0.131 & 0.131 & coincident \\
\hline $\mathrm{SE}(\mathrm{B})-3$ & 11.36 & 19.82 & 19.64 & 0.578 & 0.082 & - & - \\
\hline SE(B)-4 & 9.93 & 19.55 & 19.56 & 0.508 & 0.295 & - & - \\
\hline $\mathrm{SE}(\mathrm{B})-5$ & 11.02 & 20 & 19.93 & 0.553 & 0.685 & 1.142 & after \\
\hline SE(B)-6 & 10.00 & 19.95 & 19.95 & 0.501 & 0.727 & - & - \\
\hline $\mathrm{SE}(\mathrm{B})-7$ & 10.05 & 19.97 & 19.96 & 0.504 & 0.382 & 1.502 & after \\
\hline SE(B)-8 & 9.53 & 18.97 & 18.95 & 0.503 & 0.211 & 0.438 & after \\
\hline $\mathrm{SE}(\mathrm{B})-9$ & 10.6 & 20.04 & 19.75 & 0.537 & 0.464 & 0.718 & after \\
\hline $\mathrm{SE}(\mathrm{B})-10$ & 10.14 & 20.07 & 20.06 & 0.505 & 0.623 & 1.041 & after \\
\hline
\end{tabular}

Table 6. CTOD values, tensile specimens ( $\mathrm{SE}(\mathrm{T}))$.

\begin{tabular}{|c|c|c|c|c|c|c|c|}
\hline Specimen & $\mathrm{a}$ & $\begin{array}{c}\mathrm{B} \\
(\mathrm{mm}) \\
\end{array}$ & $\begin{array}{c}\mathrm{W} \\
(\mathrm{mm}) \\
\end{array}$ & $\begin{array}{c}\mathrm{a} / \mathrm{W} \\
(\mathrm{mm}) \\
\end{array}$ & $\begin{array}{c}\delta \mathrm{m} \\
(\mathrm{mm})\end{array}$ & $\begin{array}{c}\text { Spop-in } \\
(\mathrm{mm})\end{array}$ & $\begin{array}{c}\text { Pop-in occurrence with respect to } \\
\text { maximum load plateau }\end{array}$ \\
\hline $\mathrm{SE}(\mathrm{T})-1$ & 9.01 & 19.89 & 19.62 & 0.459 & 0.443 & - & - \\
\hline $\mathrm{SE}(\mathrm{T})-2$ & 9.18 & 19.7 & 19.67 & 0.466 & 0.421 & - & - \\
\hline $\mathrm{SE}(\mathrm{T})-3$ & 9.28 & 19.93 & 19.62 & 0.473 & $\&$ & 0.095 & before \\
\hline $\mathrm{SE}(\mathrm{T})-5$ & 10.4 & 19.83 & 19.76 & 0.526 & 1.248 & - & - \\
\hline $\mathrm{SE}(\mathrm{T})-6$ & 8.84 & 19.63 & 19.59 & 0.451 & 1.659 & - & - \\
\hline $\mathrm{SE}(\mathrm{T})-7$ & 9.58 & 19.50 & 20.00 & 0.479 & 1.444 & 1.444 & coincident \\
\hline $\mathrm{SE}(\mathrm{T})-8$ & 10.28 & 19.85 & 19.70 & 0.522 & - & 1.045 & before \\
\hline $\mathrm{SE}(\mathrm{T})-9$ & 7.9 & 19.00 & 19.00 & 0.416 & 1.068 & - & - \\
\hline $\mathrm{SE}(\mathrm{T})-10$ & 9.77 & 20.01 & 20.00 & 0.489 & 1.383 & - & - \\
\hline $\mathrm{SE}(\mathrm{T})-11$ & 10.65 & 19.20 & 19.26 & 0.553 & 0.922 & 1.145 & after \\
\hline
\end{tabular}

\&: It could not be possible to evaluate CTODm.

crack would grow reaching the maximum load value before sampling a LBZ. It would also be possible that the loss of constraint due to ductile crack growth causes a lower peak stress value at maximum load plateau, not producing brittle crack growth even when potential LBZ were sampled previously on the crack front.

Referring to loss of constraint, $\mathbf{S E}(B)$ and $\mathbf{S E}(\mathbf{T})$ specimens present very different behaviors when cracks grow in a stable way, being considerably larger in the latter specimens ${ }^{10}$. This would explain the difference in pop-in occurrence between the analyzed specimen types.

Brittle fracture initiation, when manifested, was always arrested (pop-in phenomenon). The amount of load drop was different in $\mathbf{S E}(\mathbf{B})$ and $\mathbf{S E}(\mathbf{T})$ tests. In the first ones, the average load drop was $9120 \mathrm{~N}$ (64\% of the load at pop-in initiation) whilst in the latter the average load drop was only $3259 \mathrm{~N}$ (3.3\% of the load at pop-in initiation). As it can be seen, there is a great difference in the average load drop between $\mathbf{S E}(\mathbf{B})$ and $\mathbf{S E}(\mathbf{T})$ specimens. This would be in accordance with the conclusions of Arimochi et al. ${ }^{2}$ : they found that a pop-in crack is easier to be arrested in an infinite body subjected to tensile load than in $\mathbf{S E}(\boldsymbol{B})$ tests if the unstable crack extension is shorter than certain critical crack length. In this way the load drop would be lower in $\mathbf{S E}(\mathbf{T})$ configuration than in $\mathbf{S E}(B)$ one.

The median value for CTODm in SE(T) tests is greater than the one corresponding in $\mathbf{S E}(\mathbf{B})$ tests. As CTOD values at maximum load depend on specimen geometry and specimen size, it would not be correct to compare CTODm 
values between $\mathbf{S E}(\mathbf{T})$ and $\mathbf{S E}(\mathbf{B})$ tests. Some other factors would also have influence on this discrepancy:

- different methods for the measurement of displacement were used: in SE(T) tests CTOD was directly measured on the specimen surface (*5), while CTOD in SE(B) tests was calculated, according to BS 7448: Part 1, using the geometric relation between CMOD and CTOD;

- as ductile crack growth produces more constraint relaxation in $\mathbf{S E}(\mathbf{T})$ specimens than in $\mathbf{S E}(B)$ ones, maximum load toughness will be larger in $\mathbf{S E}(\mathbf{T})$ tests.

\section{Conclusions}

1) A method for the reproducibility of pop-ins in laboratory testing consisting in the combination of welding procedure and crack orientation was introduced.

2) TS specimens showed a significantly greater percentage of pop-in occurrence than TW specimens. This would be a consequence of a difference in either the amount or in the disposition of LBZ near the crack front in both specimen configurations.

3) By using SEM and optical microscopes it was observed that the pop-in initiation point was located in coarse grain regions in all cases.

4) Brittle fracture initiation, when manifested, was always arrested (pop-in phenomenon) in both loading states.

5) Occurrence of pop-in was more frequent under bending loading than in tensile loading, in accordance with other authors observations.

6) Although further work must be led in order to explain the pop-in occurrence frequency difference between $\mathbf{S E}(\mathbf{T})$ and $\mathbf{S E}(\mathbf{B})$ tests, the different constraint relaxation in each geometry due to ductile crack growth would play an important role.

7) Most pop-ins occurred after the maximum load plateau was reached. The absence of LBZ near the crack front and/or the loss of constraint due to ductile crack growth would explain this. Simply by lowering the test tempera- ture, the methodology introduced here could lead to pop-in occurrence before maximum load plateau is attained.

\section{Acknowledgments}

The authors wish to thank Mr. Carlos G. Rodríguez Anido and R.A. Servicios Especiales company for the specimens welding, and Pablo Bilmes for his collaboration in the microscopic examinations.

\section{References}

1. Machida, S.; Miyata, T.; Toyoda, M.; Hagiwara, Y. Fatigue and Fracture Testing of Weldments, ASTM STP 1058, p. 142-156, 1990.

2. Arimochi, K.; Isaka, K. International Institute of Welding, IIW Doc.X-1118-86, 1986.

3. Koçak, M.; Terlinde, G.; Schwalbe, K.-H.; Gnirss, G. The Fracture Mechanics of Welds, EGF Pub. 2, p.7795, 1987.

4. Satoh, K.; Toyoda, M. International Institute of Welding, IIW Doc.X-1063-84, 1984.

5. Willoughby, A.A. International Journal of Fracture, 30, R3-R6, 1986.

6.Draft ASTM Test Method for Fracture Toughness Testing of Welds, ASTM E24.06.05.

7. Sumpter, J.D.G. International Journal of Offshore and Polar Engineering, v. 1, n. 3, p. 208, 1991.

8. Sumpter, J.D.G. Fatigue Fract. Engng Mater. Struct., v. 14, n. 5, p. 565, 1991.

9.BS 7448: Part 1. Fracture Mechanics Toughness Tests. Part 1. Method for Determination of $K_{I C}$, Critical CTOD and Critical J Values of Metallic Materials, 1991.

10. Schwalbe, K.-H.; Hellmann, D. CKSS Forschungszentrum, Geesthacht GmbH, GKSS/E/37, 1984. 